\title{
The General Method Study and Practice for Trans-disciplinary Design in Internet Platform of 3D Art Museum
}

\author{
Jianwen Song $^{1}$ and Zhijie Yao ${ }^{2}$
}

\author{
${ }^{1}$ Institute of Interactive Arts and Technology, China Academy of Art \\ 2 Design Study Department, Design School, China Academy of Art
}

\begin{abstract}
In the digital era of rapid development of computer software technology, the collaboration of science and arts becomes trend of development in terms of digital media content design and innovation. Breakthrough to the traditional working model, such as individual or independent small scale research and development team, establish a research and development team that consisting of artists and software engineers in art school, and do collaborative research and development project is a necessary requirement for the progress of the digital age. This paper focuses on China Academy of Art Online Gallery project that integrates the transdisciplinary resources. By using art, technology, software engineering practice and quality management methods together, this project attempt to explore a set of basic methods of combining art and science to improve the standard of creation, research and design for China's Internet 3D technology platform. It is important to break with the traditional narrow way of thinking boldly and explore the general methods of multi-team collaboration for innovative projects. It has far-reaching strategic and practical significance for digital technological innovation research in art \& design, online game and animation industry.
\end{abstract}

Index Terms - Transdisciplinary collaborative design; Technologies of the Internet platform; General methodology; User experience;

\section{INTRODUCTION}

It has been 20 years, since three--dimensional images designed specifically for the world wide web of the Internet markup language VRML (Virtual Reality Modeling Language) in 1994 VRML from initial VRML R1.0 in 1994, VRML97 in 1997, to Web3D Alliance (formerly known as Association of VRML) publishes the X3D standard ${ }^{[1]}$ in 2002, 3D Internet technology developed rapidly. In the process of this 3D internet technology development, we can tell the visual effect of the internet is directed by the requirement from the software engineers' innovation. In a long period of time, the visual effect is not satisfactory.

Today, the Internet 3DWeb design has went into the business application level from a purely technical level, Visual effect of a Web page is also changed gradually from meet the technology needs of software engineers only to meet the aesthetic demands of users.

Manuscript Received on April 12, 2011

E-mail:songjw888@163.com
Three-dimension of the Internet Web site design is not only exist as a independent technical system in Internet environment, it will enter the stage of integration of technology and art inevitably, which would herald the new age of three-dimension technology platform design is coming. In this stage, technology, business models, collaboration of art and technology, users' interaction with each other will be organized in a holistic system.

By selecting this research subject, we are trying to build up a multi-team that combines creative artists and software engineers. This team will collaborate for 3Dweb technology project of internet environment in a same area. The concept aims to present the strength from different teams, and explore the general methods of multi-team collaboration for innovative projects. It has far-reaching strategic and practical significance for digital technological innovation research in art \& design, online game and animation industry.

\section{THE 3D TECHNOLOGY DEVELOPMENT STATUS IN INTERNET}

\subsection{Development status in abroad}

\subsection{1) VRML Technology platform}

The full name of the virtual reality modeling language VRML, is recognized by the ISO international standard. In the VRML standard defines: 1) describes the encoding format of 3D models, 2) describes the interaction or script code and behavior patterns.

VRML defined in the prototype sensor nodes, routing, JavaScript, and a series of complete animation and interactivity. As VRML technology development on skeletal animation and geographical coordinates, and other extensions at the same time, Web3D Union was published in the X3D Architecture uses the latest in special effects, including multiple textures/drawn many times, Shader shaders, MRT delayed rendering and late effects.

\subsection{2 ) Other major international 3D technology platform}

1) Flash 3D platform, is one of the most widely used technology platform from Adobe Company in the Internet environment. Flash 3D initialize faster, has wide users, technology platforms fit for small featured three dimensional display, but there is room for improvement in cross-platform technology, the main problem is that Flash is not supported on the Apple system technology systems.

2) Java 3D technology platform that Sun Company released 
the first technology platform in the Internet environment. Its main advantage is that cross-platform, with a wide range of users, for small three-dimension display function.

3)Apple 3D technology platform is Apple company-published in Internet technology platform. Its advantages are cross-platform, with a wide range of users, for 360-degree loop shows feature.

To sum up, in the context of the current internet environment, platform technology that based on the 3D technology and existing presented project on internet are all supported by the small scale display feature.

\subsection{Development status in China}

The technology applications start so quickly in the 3D Web pages in China. There are many companies dominated by three dimensional Web technology for business, mainly for real estate sales, fashion, museums, art galleries, car sales show, and so on. Most Internet content demonstration project in 3D are the use of foreign technology platform. Recently, Virtools made by France DS company and Act-3D B.V company Quest3D in United States are two popular engines used in colleges and universities in China, that a lot of the small digital media content production is made by it.

Their common features are have friendly interface, easy to use, easy to grasp, but initialized slower. In 3D website system that use these technologies, display become be the main technical performance capabilities.

Online Expo is a online technical system released by Crystal Digital Ltd on May 2010. With rich content, active scenes, content directed webpage and animated form; it becomes the most representative and largest internet technology system in China since then.

\section{THE GENERAL METHODS OF TRANSDISCIPLI- NARY COLLABORATIVE PLAN IN 3D ART MU- SEUM}

Transdisciplinary collaborative plan refers to interdisciplinary cooperation, that artist team and software design team complete a same research tasks. Team is made up by the multimedia page design teachers, museums theory and art history teacher, graphics technology programming Engineer. There are big differences in terms of the way of thinking and communication when team members were trying to work together from different background. Aim to solve this problem as soon as possible, this project starts from understanding the development of modern Museum, and then come up with proposals about 3D art platform for basic needs, Web site design and software programming gradually.

\subsection{Understanding the history of the modern museum}

In 1946, "Museum", is regard as a term that covers all art, technical, scientific, historical or archaeological material open to the public. The function of museum is to show the collection.

In1961, it began to emphasize the cultural values and social function of the museum. By focusing on the purposes of research, education and appreciation, it preservation and display the collections with cultural and scientific significance.

In 1974, the Museum is non-profit permanent institutions that serve society and other development, open to the public. For the purposes of research, education and appreciation of collection, it preserves research, communicate and present material evidence of the man and the environment. The types of the museum have been divided into: Historical Museum, Arts Museum, Science Museum and Integrated Museum.

'The Quebec Declaration' in 1984 marked the birth of a new museology. New museology is a theory of museology that believe humankind is facing ecological and environmental damage problem and global society moral problem. Therefore, the new museology is not only preserve human civilization, history and culture, but also focus on community development, reflecting the progressive forces and with the future development of the community today.

\subsection{The basic connotation of new museology}

New museology is differing to the traditional idea of museology. Contrast with the principle of traditional Museum: consolidation, preservation, study and display of collections, new museology pay more attention to the community demand, it promoted Pop-Museum and the protection of cultural heritage as a whole.

New museology includes: ecological museology, community museology, and other forms of museology.

The core principle of New museology are: 1) caring about community and its demand, serve community and specific groups particularly and help people aware the characteristics of social civilization development; 2) expand the function of museum, real objects or personal properties, tangible and intangible collection from local communities all become the target object to be collected and preserved; 3) Combination of museum and education, coordinate the ecological relationship between human and natural environment .

\subsection{From new museology to online art museum}

New Concept for the Art museum directed by new museology

1) Represent the back stories of the collection dynamically. The traditional museology focus on the traditional museum working methods, ignore the intent, look at the collection as individual fixed objects instead of the live pieces with context. On the contrast, new museology claim the meaning of collection is not inherent, but can be represented differently by using the changing context and order artificially.

2) Create dynamic social connection. New museology believe that business, marketing and entertainment should be concerned that looked as extraneous issues in traditional museology.

Study on the different levels of audiences' view on museums and exhibitions

\subsection{Requirements and concepts of three dimensional art de- sign group}

Understanding the modern Museum development thread, help the design team reorganize the concept from history and professional point of view. This claim an important proposition: what is the online art gallery? And then, we made a brief according to the demands of the online art gallery. 
There are 8 basic and essential needs in online art gallery: display, collection, appreciation, classification, research, education, the arts community, Office Automation, etc.

1) Display: display is the Museum's most basic needs, the issues include:

(1) exhibit artistic expression of the arts, artist's artistic creativity; (2) people communicate with exhibits, improve participants' the taste of artistic expression, mobilize the inspiration of the visitors ; (3) emphasized the environment against the background of art; (4) use of scatter, distributed display.

2) Education: meet the needs of art education and distance education for publics.

3) Collection: the collection is the most traditional function of art museum, is core foundation to a gallery.

4) Appreciation: fully mobilize popular aesthetic judgment, and aesthetic values, for which designs need to look at a few online art gallery problem: (1) the user feeling is high involved; (2)mobilize knowledge and sensory inputs when visiting; (3) have a sense of accomplishment after the visit; (4) Multiple and repeated nature.

5) Research: research is one of the fundamental work museums should focus on as an institute:

(1) Material, techniques of artistic creation; (2) Growth story of the artist and relevant art style caused by that; (3) Art history; (4) Art criticism, and so on.

6) Art community: caring about community is a new basic connotation of museology. It is very important to build arts communities in online art gallery. The single function of display and collection is not strong enough to achieve the social goal of a new museum, especially by combining the specific feature of the internet. Therefore, it is meaningful to create an online art community that can make artists, students, art lovers and relevant professional people gathering in a platform. This platform will be a virtual user centre provides public information and interaction experiences, by using the internet technical feature.

7) Classification: a category of important technical aspect of the Art Museum, retrieved online, not just for users easy brown, but also provide the basic pattern of art content is hosted, it directly determines the internal search engine designing methods.

8) Office Automation: Three dimensional art museums have quite common management system compare with physical museum, which laid the foundation for Museum of Office Automation. Office automation solution for the problem is:

(1) Real collection and management of digital collections that corresponds to the one by one;

(2) Entity combination of geographic information and the security of the Museum Collections;

(3)Daily management specification of the physical collections, digital collections, and so on.

\section{QUALITY MANAGEMENT FOR SYSTEM DESIGN AND IMPLEMENT}

\section{1 quality management for system design}

\subsection{1) Document constructing in collaborative research and development process}

In the process of cross team collaboration, art document and technology document construction is very important. With the development of the working phase, the document full record of the research subjects in the process of planning, research project needs analysis, interface design, technical feasibility studies, detailed design of the technical system data summary reports, technical analysis, and other important technical information.

1) Documents and format numbers design

In the construction of the document, it is very important to have a unified form design for the management of a research project. It determines the basic ways of communicating, improve document of daily work, become a common language for cross-border work mode, thus avoiding unnecessary duplication of effort and rework as well as by reason of any understanding of the events of the different linguistic ambiguity.

In the construction of the document, document number is one of the important methods of specification documents; the document number is usually a four-stage method design of letters and numbers, such as early document number for this subject: CAOA_WEBARTMUSEUM_0110_001. Its basic meaning is: CAOA is China Academy Of Art in English, WEBARTMUSEUM is the online art gallery, 0110 representative beginning in January 2010, 001 is the document the construction of the first book.

2) The joint team meeting \& records

Team periodic joint meetings on research has a very positive role, it is a tie of transdisciplinary collaborative work, joint meetings of the team's main tasks are: (1) periodic progress reporting; (2) encountered in the progress of matters requiring coordination; (3) issue solution; (4) next work cycle, such as what do I need to adjust.

After each joint requires detailed records of the meetings, participants on the content of the conference to confirm and sign to ensure meeting attendees is based on the contents are accurate, clear directions.

3) Phased results archive management

Due to the work process, in recurrent revision and adjustment of system design, therefore, teams work together phased results classification, a book in a timely manner, archiving to avoid version confusion resulting from modifying the document's content in the process.

\subsection{2) Collaboration of the whole procedure quality control}

Cross-border collaborative work, process standardization is key link of this team work. full process quality management is use quality management thought as foundation, from planning, design, research, development, debugging and completed; all members work by following unified work mode, and grope out own work mode in practice: three a system, five item standard.

1) professional group dividing and work assignment system: team according to their respective constituencies by the staff of general work cycle of research and development on issues and tasks assign development tasks design, with a clear work objectives, research fields and to determine the workload 
of that assignment. Assignment also provides reference sources, resources related to libraries, information and other content.

Professional groups are divided into:

Art design and planning group: members of this group organized by the artists and engineers, primarily responsible for project planning, interface design, content and data provided, and so on.

Database technologies group: responsible for enterprise-level database system design for technology development.

Internet technology group: responsible for the technical implementation of Internet art gallery system.

2) System of weekly summary: Weekly summary on project of research and development is necessary. In the project development process, new problems and new ideas constantly appear. Since innovative ideas won't be realized $100 \%$ because of practical reasons, so if you want to actually enter development process, teams are required to evaluate their development process regularly. Weekly summary will make evaluation of an innovative idea if it is operational, and identify and analyze the important work should be done in the coming week.

3) Meeting record system: Meeting summary is memorandum of team work. Meeting record is helpful for every participants to have a clear understanding of, meeting and emphasize the key work after the meeting. Meeting record should have a unified file format: (1) Meeting theme; (2)Locations and time; (3) Solved problems; (4) Solutions; (5) assessment and implementation plan for the innovation; (6) Signature of the participants.

4) Programmers work standards: Establish cross-border research and development technical for programmers working standards is one of the important tasks of team management, the programmer's work is rigorous and orderly. Code style is unified; Programmer's daily behavior conforms to the specification to be investigation of important judgments based on programmer himself and the outcome of the work.

5)Resources management standard: Resources management main include: (1) Resources library (pictures, and model, and code); (2) Original information (research information, and project research and development process of between letter); (3) Professional information (staged results compilation); (4) System source code; (5) Meeting summary of compilation; (6) Books and information, project, across territories research and development must will information management into specification of management areas, to ensure project research and development process of ordered for.

6) Program code named standard: Program code maintainability is the program of technical systems in the development process of core issues. Not professionally trained programmers, each with its own habits, these habits is very harmful to the project.

7) Technical system testing standard: Technical system debug is a very important work that related with system research and development and clients' usage in the future. So, establishing technical system testing standards allows the programmer to accurately grasp the key points when they working on the programme properly. Such as a function of the border issue, system compatibility, system stability issues, workarounds for most likely to occur in the programming issues, technical system testing outside of the standard also provides system debug programmer must be recorded by a non-technician's evaluation record.

8) Research achievement archives standards: Project research, development results or the ultimate technology project research and development achievements are collected in this stage. This archives collect is an important project management work related to the project for future maintenance and upgrades.

Project Standard mainly determine the outcome of research and development: (1) the title of the, (2) content of the outcome; (3) finishing time; (4) version of the outcome; (5) results of major technical framework; (6) line of key technologies and algorithms; (7) results approval, experts' opinions and archived content.

\subsection{Technical systems design}

It is consist of technology of 3D technology, Web technology, Internet services, hardware, server group, expand the Internet technical standards for 3D Web clients, Web site content for Internet system is a $3 \mathrm{D}$ technology.

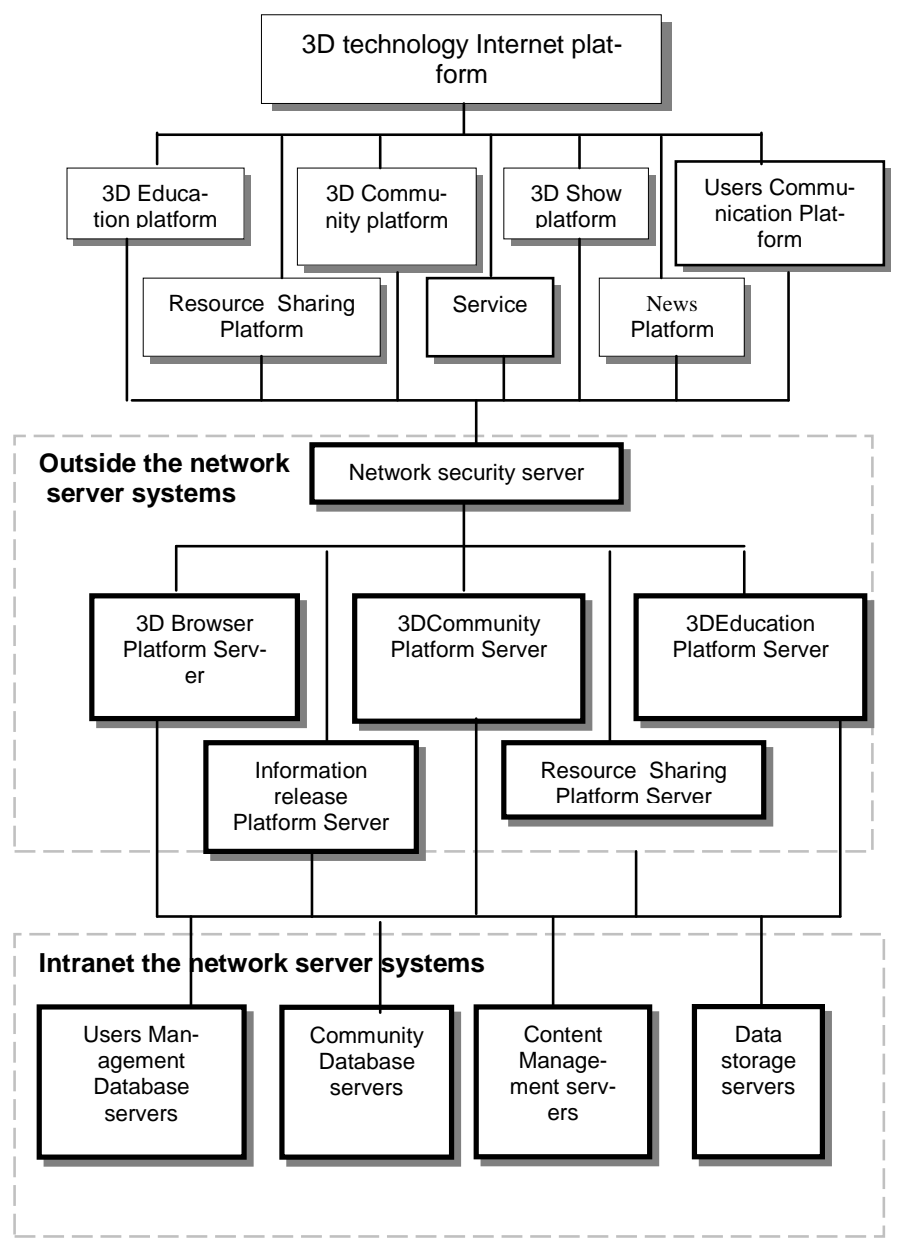

Fig.1. sketch of three dimensional art museum technology platform based on Internet 


\section{DESIGN PRACTICE OF CHINA ACADEMY OF 3D ART MUSEUM IN INTERNET}

\subsection{Online art gallery construction significance of project}

This project of construction should meet the needs of art museum's various collections management, Office Automation of needs, implementation pavilion literature information, and art and exhibition resources shared, established museum digital management system and digital 3D network display system has imminent, hardware and software device management, and collections' digital bilingual version of wrote and entry, and 3D website construction and exhibits exhibition item scenario display digital created.

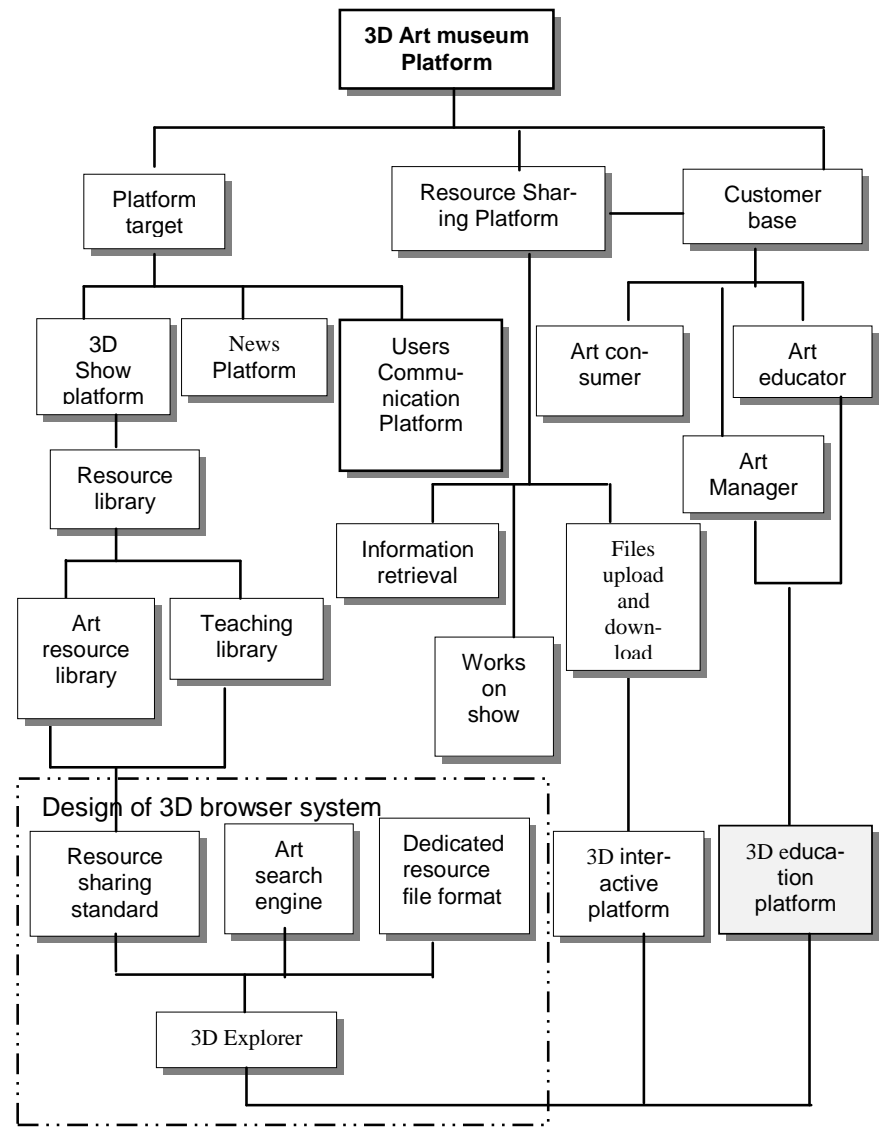

Fig. 2. Sketch of three dimensional art platform based on Internet

\subsection{Characteristics of the China Academy of Fine Arts Gallery}

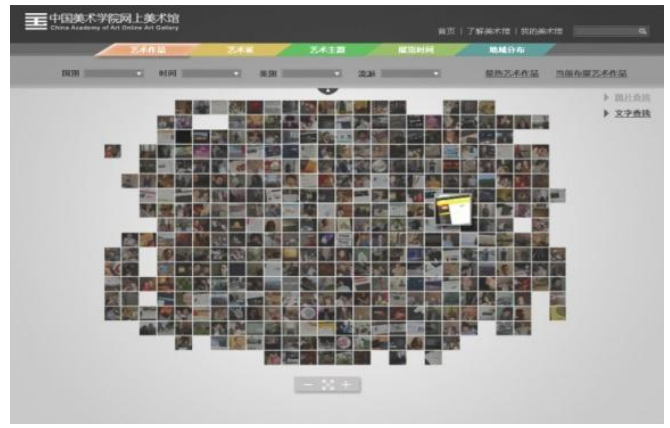

Fig. 3. Index Page of the 3D art museum (Color Plate 10)
Construction of the China Academy of Arts Gallery showing property is different from traditional independent Museum,

it has:

1) multi- located (covers Nanshan campus, Xiangshan campus and the Shanghai Branch, three Senior Colonel);

2) Wide coverage (distribution in the campus has many galleries on display);

3) All exhibits are art piece .

\subsection{Logical data structure design of $3 \mathrm{Dl}$ art museum on the} Internet

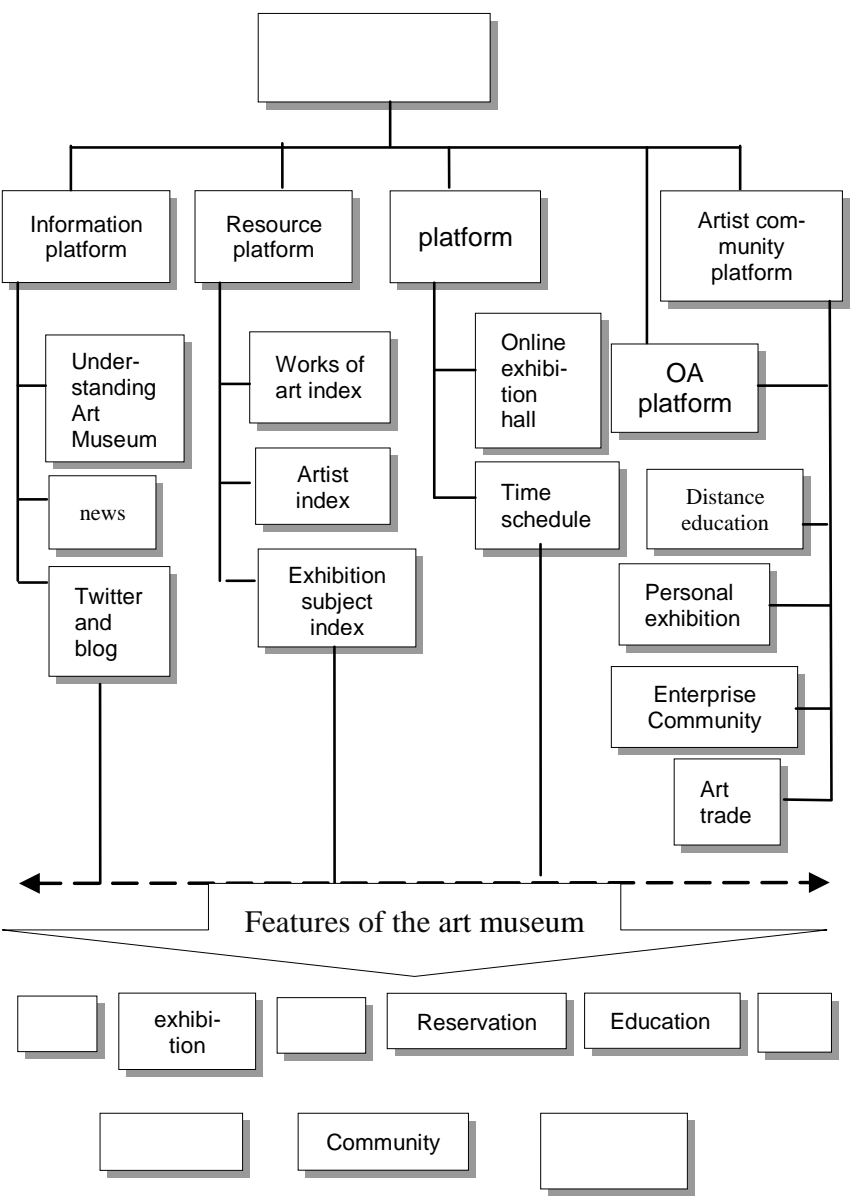

Fig. 4. 3D art museum Internet logical data structure diagram

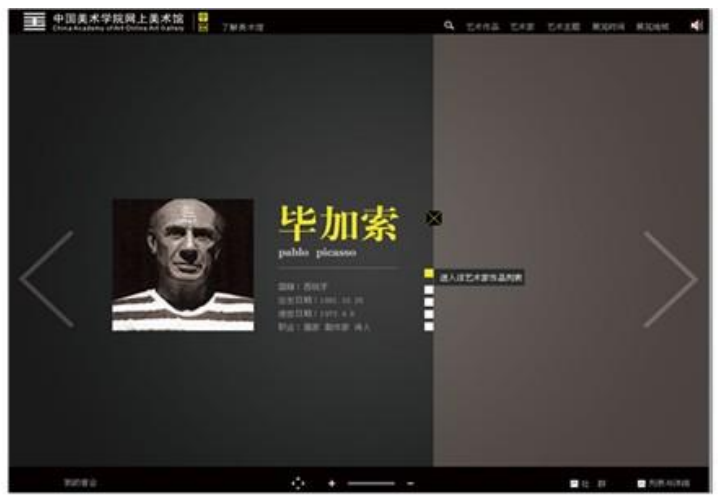

Fig. 5. Pablo Picasso Page of the 3D art museum 


\subsection{Internet technical properties of three dimensional art gallery location}

Comprehensive portal sites by displaying it in three-dimensional interaction as the core technology platform, including:

1) Museum of client systems on the Internet;

2) Server group technology systems;

3) Technology systems management system;

4) Art Museum, the day-to-day management of the standard system.

\section{THE KEY TECHNOLOGY REALIZATION IN IN- TERNET}

\subsection{The technology platform for running and build environment}

Environment for the running of the project: runs on the Microsoft Windows Xp and above, the minimum configuration for: $300 \mathrm{G}$ your hard disk, memory $2 \mathrm{G}$, display memory is $256 \mathrm{MB}$.

This project's build environment for: graphics engine to version OpenGL2.1, SQL_Sever 2008 database queries, VS2008 project compilation platform.

User client: this project is based on IE browser ActiveX controls run client-side technologies. Design of the system is not using Flash technology.

\subsection{Key technology and implementation}

1) Large amounts of data transfer problem: Under the condition of limited bandwidth of the Internet, a large number of data transfers become the key technology of three-dimension technology platform. Technology solutions of this project is to transfer data design as standard a wealth of information, the information usually is $80-100 \mathrm{k}$ around, real time multithreaded downloading method in the background, step by step load complete.

2) Single on the multi-windowing technique of 3D framework of the process: On the analysis of the user's experience, we found that most users ' habits are like window switching, they are in the same process and technologies under a single process. It is quite easy to achieve on a single $3 \mathrm{D}$ window.

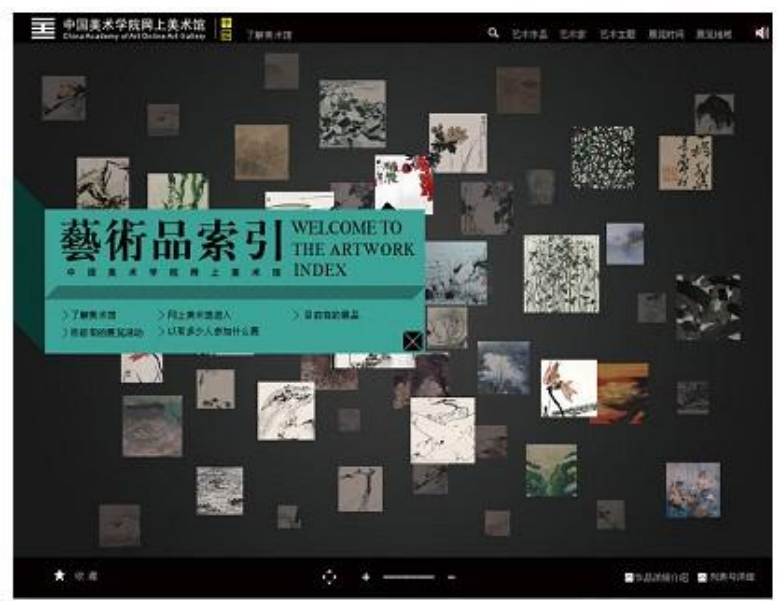

Fig. 6. Works index page of the 3D art museum (Color Plate 11)
Achieve in a single process, the child pages of the technique of three dimensional multi-windowing technique for autonomous independent development framework is a key technology for links. This project will insert multiple ActiveX controls in the course of a single client, enable initialize after the completion of the ActiveX control to work in parallel.

3) With user experience at its core: user experience survey, we found that typically, users of a site initialization tolerance period for not more than 30 seconds. If more than 30 seconds, most of users will give up. Therefore, initialization problems as the 30 second user stickiness design of critical points.

This system is designed to address this segment initialization method initializes issues, to initialize the data is divided into three phases: 1) starting from the users visit our site, and began the work of initializing the background so that you can use system initialization time of 10 seconds in advance, when the user invokes the other three dimensional window, initialization is not more than 10 seconds to complete. After the initialization is complete, the system can be window switch and run smoothly.

\section{CONCLUSIONS}

Today computer digital develop rapidly, different area and professional of mutual fusion is significant feature and inevitable development trend in digital era. However, due to different professional respective limitations, people want to complete an item innovation of research and development task is comparison difficulties without a unified of communication and work exchange mode. This paper analysis this issue from research and actual work, and conclude with the general methods of doing transdisciplinary research and development for a project. This method focus on the cooperation of different professional area, especially collaboration between art team and technology team proved a good case study.

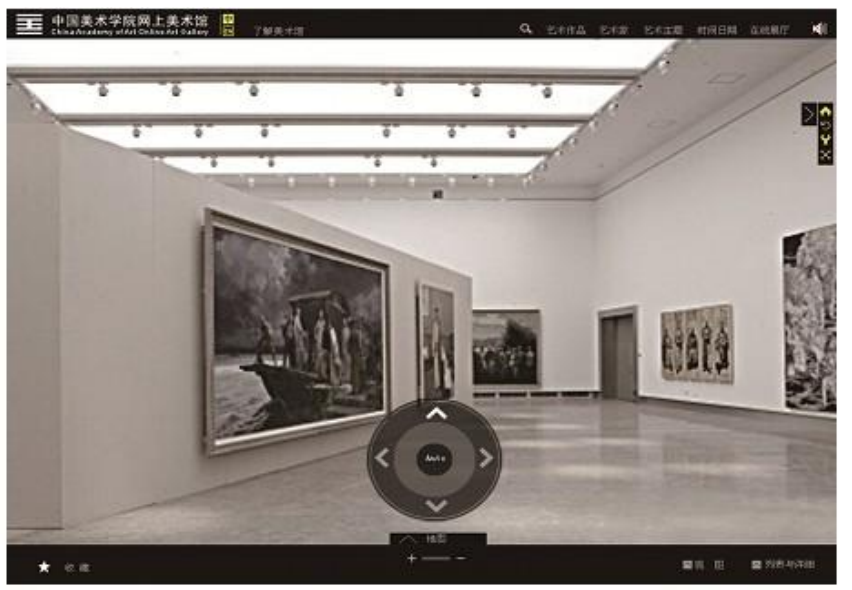

Fig. 7. 3D Online exhibition hall (Color Plate 12)

Transdisciplinary innovation design, taking the road of China's independent resear ch and development, and find the position in international professional stage is inevitable requirements in China digital era. Therefore, artists and engineers 
work together to improve the quality of life in China and take it towards a prosperous and powerful challenge. It has practical significance and far-reaching strategic significance that create general methods for transdisciplinary development projects, further enhanced and summarization in theory and in practice in our country which becomes an innovation-oriented country.

\section{REFERENCES}

[1] ISO/IEC FCD19775, Extensible 3D(X3D) Specification, Final Committee Draft[S] .

[2] Extensible 3D(X3D) Graphics, XML Tagset [EB/OL] . http://www.web3d.org/TaskGmups/x3d/x3d-tags.html,2002-03-30

[3] Aijun Xu, Wenjin Zhang, Dan Yi, (Guangzhou Institute of Railway Technology, Guangzhou 510430); Virtual Reality Technology and Applications Based on VRML[J];Computer \& Digital Engineering;2009-04

[4] M. White, F. Liarokapis, N. Mourkoussis, A. Basu, J. Darcy, P. Petridis, M. Sifniotis, P. Lister, Dept. of Informatics, Sussex Univ., Brighton ; ARCOLite-an XML based system for building and presenting virtual museum exhibitions using Web3D and augmented reality; [J]; Theory and Practice of Computer Graphics, 2004. Proceedings; pp94 - 101

[5] Bing-Yu Chen, Tomoyuki Nishita Development of 3D graphics and VRML libraries for Web3D platform by using Java; [J]; Systems and Computers in Japan, 34(10), pp. 47-55, September 2003

[6] Stefano Tornincasa, Emilio Chirone , The Leonardo Webd Project: An Example of The Web3d Technology Applications for Distance Training and Learnixiv; Congreso Internacional de Ingeniería Gráfica Santander, España - 5-7 junio de 2002NG

[7] Tomaz Amon, Slovenia Teaching biology in primary and secondary schools with the help of the dynamic HTML and web virtual reality (web3D) projects; [J] Interactive Educational Multimedia, number 4 (April 2002), pp. 89-98

[8] John T. Bell and H. Scott Fogler; Implementing Virtual Reality Laboratory Accidents Using the Half-Life Game Engine, WorldUp, and Java3D; Proceedings of the 2003 American Society for Engineering Education Annual Conference \& Exposition Copyright $\odot$ 2003, American Society for Engineering Education;

[9] UNESCO "Museum" Museum management information index $(1-25 \mathrm{Vol})[\mathrm{J}]$; China Museum;1985-02.

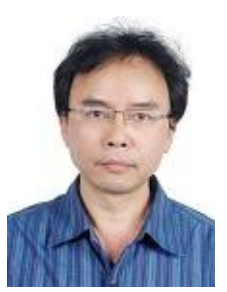

Jianwen Song was born in 18th of August 1959 in Fuzhou China. Song had BA degree in Shandong Metallurgical Industry University. Song's major field of study is online computer graphic research, game programming and web3D research and design. Song has been doing education work in the relevant field for long time.

$\mathrm{He}$ is an associate in School of Media and Animation, China Academy of Art. And he is also teaching as tutor for MA student. He was supported by the National Social Science Foundation of Art 2011 with research project 'Foundation and System Implementation Research for Color Digital Design '; was supported by 2010 Fujian Social Science project with 'Study for the internet platform of operation and management for sport-based tourist resources'; was supported by China Color Technology Award by 'Software for Color Design Education'.Prof. Song is member of Digital Arts Professional Committee, Chinese society of image and graphics.

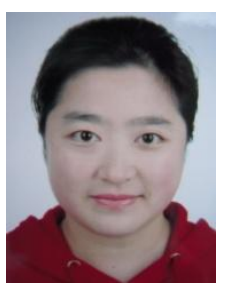

Zhijie Yao was born in $3^{\text {rd }}$ of December 1978 in Hangzhou China. Her first MA degree is 'Design Futures' in Goldsmith College, University of London, 2004. Second MA degree is 'Creative Practice for Narrative Environments' in Central Saint Martins College of Arts and Design, University of the Arts London, 2006. Yao's major field of study is 'Curating for Contemporary Design' and 'Design Critique \& Anticipation'.

She is lecturing in Design Study Department, Design School, China Academy of Art, also work as design critic \& creative industry producer in vary social and research project. Her publications include $<$ When Design Encounters Expo>,

$<$ The Exit to Tomorrow-New Design Age in Post-expo Era $\rangle,\langle$ Mapping a Dynamic Environment for Design $>$. Her current research 'Research for international Contemporary Design Exhibition: Comparing Curatorial Systems for International Design Festivals' is funded by China Artist Association. 